Elsevier Editorial System(tm) for Journal of Cleaner Production Manuscript Draft

Manuscript Number: JCLEPRO-D-15-00934R1

Title: Automated registration of potential locations for solar energy production with LiDAR and small format photogrammetry

Article Type: Original Research Paper

Corresponding Author: Dr. Szilárd Szabó, Ph.D.

Corresponding Author's Institution: University of Debrecen

First Author: Szilárd Szabó, Ph.D.

Order of Authors: Szilárd Szabó, Ph.D.; Péter Enyedi; Miklós Horváth; Zoltán Kovács; Péter Burai, Phd; Tamás Csoknyai, PhD; Gergely Szabó, Phd

Abstract: Energy production and consumption is a key element in future development which is influenced both by the technical possibilities available and by decision makers. Sustainability issues are closely linked in with energy policy, given the desire to increase the proportion of renewable energy. According to the Horizon 2020 climate and energy package, EU member countries have to reduce the amount of greenhouse gases they emit by $20 \%$, to increase the proportion of renewable energy to $20 \%$ and to improve energy efficiency by $20 \%$ by 2020 . In this study we aim to assess the opportunities available to exploit solar radiation on roofs with LiDAR and photogrammetry techniques. The surveyed area was in Debrecen, the second largest city in Hungary. An aerial LIDAR survey was conducted with a density of 12 points $/ \mathrm{m} 2$, over a $7 \times 1.8 \mathrm{~km}$ wide band. We extracted the building and roof models of the buildings from the point cloud. Furthermore, we applied a low-cost drone (DJI Phantom with a GoPro camera) in a smaller area of the LIDAR survey and also created a 3D model: buildings and roof planes were identified with multiresolution segmentation of the digital surface models (DSM) and orthophoto coverages. Building heights and building geometry were also extracted and validated in field surveys. 50 buildings were chosen for the geodetic survey and the results of the accuracy assessment were extrapolated to other buildings; in addition to this, 100 building heights were measured. We focused primarily on the roofs, as these surfaces offer possible locations for thermal and photovoltaic equipment. We determined the slope and aspect of roof planes and calculated the incoming solar energy according to roof planes before comparing the results of the point cloud processing of LiDAR data and the segmentation of DSMs. Extracted roof geometries showed varying degrees of accuracy: the research proved that LiDAR-based roof-modelling is the best choice in residential areas, but the results of the drone survey did not differ significantly. Generally, both approaches can be applied, because the solar radiation values calculated were similar. The aerial techniques combined with the multiresolution processing demonstrated can provide a valuable tool to estimate potential solar energy. 


\section{Automated registration of potential locations for solar energy production with LiDAR and small format photogrammetry}

Szilárd SZABÓ ${ }^{1}$, Péter ENYEDI ${ }^{2}$, Miklós HORVÁTH ${ }^{3}$, Zoltán KOVÁCS ${ }^{1}$, Péter BURAI², Tamás CSOKNYAI $^{3}$, Gergely SZABÓ ${ }^{1}$

${ }^{1}$ Department of Physical Geography and Geoinformatics, University of Debrecen, Egyetem tér 1. 4032, Debrecen, Hungary

${ }^{2}$ Research Institute of Remote Sensing and Rural Development, ${ }^{3}$ University of Debrecen, Károly Róbert College, Mátrai út 36. 3200, Gyöngyös, Hungary

${ }^{3}$ Department of Building Service and Process Engineering, Budapest University of Technology and Economics

\footnotetext{
Address for correspondence:

Szilárd Szabó

Department of Physical Geography and Geoinformatics, University of Debrecen, Egyetem tér. 1. 4032, Debrecen, Hungary, tel.:+36 52 512900/22326 (switchboard), fax: +36 52 512945, e-mail: szabo.szilard@science.unideb.hu
} 
Abstract

Energy production and consumption is a key element in future development which is influenced both by the technical possibilities available and by decision makers. Sustainability issues are closely linked in with energy policy, given the desire to increase the proportion of renewable energy. According to the Horizon 2020 climate and energy package, EU member countries have to reduce the amount of greenhouse gases they emit by $20 \%$, to increase the proportion of renewable energy to $20 \%$ and to improve energy efficiency by $20 \%$ by 2020 . In this study we aim to assess the opportunities available to exploit solar radiation on roofs with LiDAR and photogrammetry techniques. The surveyed area was in Debrecen, the second largest city in Hungary. An aerial LiDAR survey was conducted with a density of 12 points $/ \mathrm{m}^{2}$, over a $7 \times 1.8 \mathrm{~km}$ wide band. We extracted the building and roof models of the buildings from the point cloud. Furthermore, we applied a low-cost drone (DJI Phantom with a GoPro camera) in a smaller area of the LiDAR survey and also created a 3D model: buildings and roof planes were identified with multiresolution segmentation of the digital surface models (DSM) and orthophoto coverages. Building heights and building geometry were also extracted and validated in field surveys. 50 buildings were chosen for the geodetic survey and the results of the accuracy assessment were extrapolated to other buildings; in addition to this, 100 building heights were measured. We focused primarily on the roofs, as these surfaces offer possible locations for thermal and photovoltaic equipment. We determined the slope and aspect of roof planes and calculated the incoming solar energy according to roof planes before comparing the results of the point cloud processing of LiDAR data and the segmentation of DSMs. Extracted roof geometries showed varying degrees of accuracy: the research proved that LiDAR-based roof-modelling is the best choice in residential areas, but the results of the drone survey did not differ significantly. Generally, both approaches can be applied, because the solar radiation values calculated were similar. The aerial techniques combined with the multiresolution processing demonstrated can provide a valuable tool to estimate potential solar energy.

Keywords: roof plane, solar irradiation, point cloud, multiresolution segmentation, drone 


\section{Introduction}

Renewable energy resources are becoming increasingly important in the structure of energy production. As non-renewable sources (such as petroleum or coal) are often considered polluters of the environment, greenhouse gas producers, or as posing a high risk (nuclear energy), it is crucial to find solutions to replace them with environment-friendly alternatives. At the same time, the EU introduced the Horizon 2020 Framework Program for Research and Innovation: the efficiency of energy should be increased by $20 \%$, the proportion of renewable energy should be increased by $20 \%$, and greenhouse gas emissions should be reduced by $20 \%$ (European Commission, 2014). Considering the private contribution by residents, an increase in the number of passive houses can represent a genuine milestone in efficiency (Kozma et al., 2013), while local energy production can decrease the GHGs and improve the proportion of renewable energy sources (Farkas, 2010; Lázár, 2011; Lewis, 2007). In this study, we focus on solar energy as a possible solution for private energy production. It is a solution which has both advantages and disadvantages. In the current economic environment, private properties are not supported to install photovoltaic (PV) solar systems in Hungary. Consequently, the high cost of installation is a serious disadvantage, but it is a solution which can offer complete or partial continuous energy for both institutions and households. Accordingly, remarkable efforts have been conducted to determine the solar potential of winemaking facilities (Smyth, 2012). Besides, there is no loss involved in the transportation of the energy. A limiting factor is that not all roofs are appropriate for installing solar panels, as this depends on the size, aspect and slope of the roof planes. Shadows generated by the roof elements, chimneys, antennas, or by the trees and pylons in the street can seriously reduce efficiency (Stevanovits, 2013).

Roofs can be detected with remote sensing techniques (e.g. Nagyváradi et al., 2013); however, a simple identification is not sufficient to assess which roofs are suitable for the installation of PV panels, as methods must be employed that can reveal the roofs' geometry. Photogrammetry and Light Detection And Ranging (LiDAR) are the two possible methods suitable for this task. While photogrammetry requires aerial photographs, and the outcome depends on the geometrical resolution and the quality of the images, LiDAR works with laser beams and the reflecting signs are recorded. Photogrammetry yields a digital surface model (DSM), while LiDAR, based on the emitted and backscattered signs with different returning times, provides a model both for the ground (digital terrain model, DTM) and the surface (digital surface model, DSM). In terms of roof detection, both techniques are suitable; we only need information about the surface of the objects (i.e. the roofs). The LiDAR technique was developed in the 1960s, but became popular only in the first decade of the 2000s. Recently, several studies have dealt with terrain and surface models derived from LiDAR point clouds. Highly detailed digital elevation models are the most popular application fields (e.g. Chassereau et al., 2011; Liu, 2008) in natural or urban environments (Ghuffar et al., 2013; Zlinszky et al., 2014) or to extract different elements of the surface, such as geomorphic forms (Dorninger et al., 2011), trees (Mücke et al., 2013), city buildings, or street furniture (Priestnall et al., 2000). 
Numerous publications have discussed the detection of buildings based on LiDAR. In research conducted by Yu et al., (2010) the accurate detection of city buildings was the aim, as in the case of Zhou and Neumann (2013). Filtering buildings was also the objective of the works of Mongus et al (2014) and Li et al., (2013). While Alexander et al., (2009) dealt with roof structure, Lukac et al., (2014) focused particularly on the potential solar radiation of built-up areas with LiDAR data. There are several research studies which have adopted a photogrammetric approach, too, ranging from the digital representation of the solar panels (Shortis et al., 2008) through solar potential estimation on a city-scale (Nex et al., 2013) to a complete survey of roof geometry (Lin and Zhang, 2014; Protic et al., 2012). LiDAR has a relevant advantage against photogrammetry as it provides data of the ground even it is covered by tree vegetation (Demir et al., 2008; Korpela et al., 2012).

Both techniques have their advantages and limits. LiDAR can be considered more reliable than photogrammetry in terms of the way data is collected: a laser beam has a footprint (i.e. a 20-40 cm diameter circle) on the surface and its size is the function of the divergence angle and the above-target flight height (Bin et al., 2008). Thus, laser beams have multiple echoes and often can penetrate vegetation and roofs covered by tree canopy, so these can also be surveyed (Shan and Toth, 2008). However, due to the footprint, the horizontal accuracy is worse than the vertical (Csanyi and Toth, 2007). A major issue with 3D point clouds is how to handle the dataset, especially in the case of surveys providing a very high point density. Photogrammetry is biased by the vegetation as it can only produce surface models. Furthermore, the technique is sensitive to homogenous area sections, periodic objects and shadows, while LiDAR is independent of them (Paparoditis and Polidori, 2004). According to Baltsavias (1999) the two technologies can be used in a complementary way to exploit the advantages of both.

Incoming solar irradiation can be computed with the involvement of slope, aspect, and shadows cast by topographic features (e.g. mounds) or other surface objects (e.g. buildings, trees, chimneys, pylons etc., Boehner and Antonic, 2009; Quazi et al., 2015). If all of these parameters are involved in a model, results can be regarded as reliable (Iqbal, 1983). Calculations can be conducted based on the appropriate equations, or software, such as ArcGIS, SAGA GIS and GRASS GIS, which provide solar radiation models (Wh'm ${ }^{-2}$ day $^{-1}$, Hofierka and Šuri, 2002; Hofierka and Kañuk, 2009; Hengl et al., 2009). All models have errors due to the underlying concept or to a lack of appropriate data, but in most cases we do not require exact values, because a good approximation of the possible maximum summed by a given time interval is sufficient.

Studies have usually been designed to determine the area of the roof planes and the incoming solar energy, but have not compared the different surveying methods. Our aim was to investigate and compare the surface models of a LiDAR survey and an aerial imaging carried out with a low cost drone system from the perspective of roof detection. We compared the resulting roof shapes and evaluated their suitability for solar panel installation for both models; furthermore, we also compared 
the incoming solar irradiation of the models. We also compared the cost-benefit issues of the drone and LiDAR based techniques.

\section{Materials and methods}

\subsection{Data collection}

A combined LiDAR and high resolution aerial imaging was carried out over a $7 \mathrm{~km}^{2}$ area in Debrecen (Eastern-Hungary). A Leica ALS70-HP and a Leica RDC 30 RGBN 60 MP were used in the survey (1000 m flight height, $780 \mathrm{~m}$ swath, sinusoid scan pattern, 20\% overlap). Point density was 12 point $/ \mathrm{km}^{2}$, which was in accordance with the suggestion made by Cekada et al., (2010). An accuracy assessment was carried out on the whole study area; however, we used only a smaller part in the analysis to investigate incoming solar irradiation, where the drone survey was possible (Fig. 1). The roofing material of the buildings in the study area was red tile, ensuring the creation of a uniform database independent of LiDAR intensity values.

\# Fig. 1. approximately here

The drone survey was conducted at average altitude of $93 \mathrm{~m}$ with a DJI Phantom quadrocopter and a GoPro Hero 3 Black edition camera (focus length: $2.77 \mathrm{~mm}$, lens size: $14 \mathrm{~mm}$ ) combined with an NDVI stress camera (XNiteCanonELPH110NDVI, focus length: $4.30 \mathrm{~mm}$, lens size: $14 \mathrm{~mm}$; LDP LLC Ltd.). The pilot area was 12 ha, falling within the area of the LiDAR survey, in the university campus (University of Debrecen).

\subsection{Point cloud processing}

The LiDAR point cloud was filtered by TerraSolid's TerraScan module in the MicroStation environment (https://www.terrasolid.com/download/tscan.pdf) over the whole area. TIN interpolation with natural densification (Lin and Zhang, 2014) was carried out for the separation of ground points, then vertical outlying points were removed using filters. Following this, we filtered out the buildings with parameterized algorithms of TerraScan. Afterwards, we extracted the vector features of the buildings as an element of a semi-automated roof identification. We aimed to find the optimal parameters to extract the minimal roof-part size to obtain the most accurate and detailed roof models. Besides, a digital surface model (DSM) was generated from the point cloud with $20 \mathrm{~cm}$ cell size (20 $\mathrm{cm}$ is the largest reasonable resolution which can be obtained from the 12 points $/ \mathrm{m}^{2}$ point cloud) in order to make a comparison (Fig. 2).

\subsection{Photogrammetric analysis}

We applied Agisoft Photoscan Pro 1.1.0. (Agisoft LLC) for the photogrammetric evaluation of 188 images taken by the GoPro 3 camera. We used 16 GCP points (measured with a Stonex S9 RTK 
system) as tie points and the highest precision option was applied to produce the model. Outlier points were filtered out with the aggressive depth filtering mode. The procedure resulted in a classic DSM with a density of 107 point $/ \mathrm{m}^{2}$, and also an orthophotograph compiled from the aerial photos. The procedure yielded a true orthophoto (proposed by Amhar et al., 1998); accordingly, both spatial coverages were used in the analysis. Both the DSM and the ortophotograph had a resolution of $20 \mathrm{~cm}$.

\subsection{Analysis of digital surface models}

Image segmentation was carried out on the DSMs, aspect and slope coverages (both the latter were derived from LiDAR and aerial images) using eCognition Developer. Image segmentation is an object-oriented analysis technique that takes into account not only the pixel values but also the texture (Blaschke, 2010); thus, contrary to pixel-based classification, "salt and pepper" type errors can be avoided (Weih and Riggan, 2010). DSM, aspect and slope coverages were segmented using multiresolution segmentation with four different scale parameters (L10, L50, L100, L200) and found that the procedure with two steps from the super-object to the sub-object using L200 and L100 values fulfilled the aims, i.e. separating the input raster coverages into the largest homogenous segments (Kumar et al., 2014; Shao et al., 2014). This procedure was repeated with the use of the orthophoto. An XNiteCanon camera was used to produce a pseudo-color orthophoto with blue-green-infra red bands, which was used to calculate normalized difference vegetation (NDVI, Rouse, 1973) values. NDVI ranges from -1 to 1 and values below zero indicate high reflectance which is characteristic of bare soil/rock or anthropogenic objects (e.g. buildings, roads etc.; Rouse et al., 1973). We applied a roof-mask compiled from NDVI values $(<0)$ and building heights $(>3 \mathrm{~m})$.

\subsection{Digital building models}

Finally, four digital representations were produced for the buildings. The representation that provided the roof plane geometry in the most realistic way was the one from the point cloud processed in a CAD environment (LPC), and a segmented digital surface model (SDSM) was produced with the segmentation method from the surface model of the point cloud. PDSM (segmented DSM) and OPDSM (common segmentation of the orthophoto and the DSM) were produced from the surface model of the photogrammetry approach.

\subsection{Validation}

We obtained field measurements with a Stonex S9 RTK GPS pair for 50 buildings to check the contours of the buildings. Besides, 100 measurements were carried out for 100 buildings with a Leica Disto D5 to control the building heights. Root mean square error (RMSE) and quartiles were reported for the calculated differences between the LiDAR data and the measured data.

Solar radiation was validated by the comparison of a building's (student hostel) roof planes based on the blueprint and the LiDAR survey. 


\subsection{Calculation of the incoming solar irradiation}

We filtered out those segments of the roof planes that were suited to the following conditions (modifying the approach of Kassner et al., 2008): slope: $20-60^{\circ}$; aspect: $90-270^{\circ}$; area: $>2 \mathrm{~m}^{2}$; compactness: $>0.3$ (Fig. 2).

\#Fig. 2 approximately here

In order to evaluate the results of the modeling procedure, a sample building was analyzed. The building analyzed was the student hostel building of the campus site (N: 47 33' 18.9000"; E: $21^{\circ} 37^{\prime}$ 24.1932"). The results of the model were compared to a validated method based on a manual approach. The data regarding the building's roof were acquired from two sources. On the one hand, they were generated automatically from the described procedure and, on the other hand, manually from a digital map. We obtained the following data: area, slope and azimuth. Roof areas have errors due to the surveying method used, i.e. the top view of the roofs results in a smaller area for roof planes. We corrected the roof areas with the cosine of the slope angles (Früh and Zakhor, 2003); the correction was made as in (Eq. 1).

$$
A_{t}=\frac{A_{h}}{\cos \left(\alpha_{M}\right)}
$$

where $A_{h}$ is the roof area measured from above (horizontal roof) $\left[\mathrm{m}^{2}\right] ; A_{t}$ is the calculated area of the tilted roof $\left[\mathrm{m}^{2}\right]$.

The number of PV panels by roof planes was determined manually, and automatically with a Python plugin developed for ArcGIS. In both solutions a $0.5 \mathrm{~m}$ buffer was omitted from the calculation, the rest of the roof plane was covered with PV panels. In the first step all available roof areas were covered with solar panels, in the second case the north facing parts of the roof were left empty.

The incoming solar irradiation was calculated for the geometrical data acquired. Solar yield calculations were performed with an anisotropic solar irradiation model (Reindl et al., 1990). The direct, diffuse and reflected radiation components were calculated according to (Eq. 2-4) and the global radiation was calculated as a sum of the components (Eq. 5).

$$
\begin{aligned}
& I_{t}=(G-D) \cdot R_{b} \\
& D_{t}=D \cdot\left\{\left(1-A_{i}\right) \cdot\left(1+\cos \alpha_{M}\right) \cdot \frac{1}{2} \cdot\left[1+f \cdot \sin ^{3}\left(\frac{\alpha_{M}}{2}\right)\right]+A_{i} \cdot R_{b}\right\}
\end{aligned}
$$




$$
R_{t}=G \cdot A \cdot\left(1-\cos \alpha_{M}\right) \cdot \frac{1}{2}
$$

$G_{t}=I_{t}+D_{t}+R_{t}$

where $\mathrm{A}$ is the albedo value [-]; $\mathrm{A}_{\mathrm{i}}$ is the anisotropy index; $\mathrm{D}$ is the diffuse radiation on a horizontal plane $\left[\mathrm{kW} / \mathrm{m}^{2}\right] ; \mathrm{D}_{\mathrm{t}}$ is the diffuse radiation on a tilted plane $\left[\mathrm{kW} / \mathrm{m}^{2}\right]$; $\mathrm{f}$ is the modulating factor of cloudiness; $\mathrm{G}$ is the global radiation on a horizontal plane $\left[\mathrm{kW} / \mathrm{m}^{2}\right] ; \mathrm{G}_{\mathrm{t}}$ is the global radiation on a tilted plane $\left[\mathrm{kW} / \mathrm{m}^{2}\right] ; I_{t}$ is the beam radiation on a tilted plane $\left[\mathrm{kW} / \mathrm{m}^{2}\right] ; R_{b}$ is the ratio of beam radiation on a tilted plane to the beam radiation on a horizontal plane; $R_{t}$ is the reflected radiation on a tilted plane from the surroundings $\left[\mathrm{kW} / \mathrm{m}^{2}\right] ; \alpha_{\mathrm{M}}$ is the tilt angle of the tilted plane $\left[{ }^{\circ}\right]$.

The meteorological conditions of the building site were described by the insolation time and we applied the Angström-Prescott method (Paulescu et al., 2013) to determine the global irradiation. Insolation data used in the calculations were measured between 1981 and 2000. Calculations were performed for three cases. Firstly, the incoming irradiation was calculated for the entire roof area of the building. In the second case we calculated the incoming solar irradiation for the solar panels which were allocated to the roof planes. In the third case the panels facing in a direction ranging from northeast to northwest were removed since these locations lead to an economically non-viable solution. In the validation process, the traditional (manual) approach based on the blueprints was regarded as providing the most realistic data. Following this we included all the registered roof planes in the analysis and calculated the incoming solar energy for each of them. We summarized the roof planes of the 13 buildings which can be found in the surveyed part of the campus area.

\subsection{Statistical analysis}

We applied non-parametric tests due to the non-normal data distribution of the roof area and solar irradiation. Our null hypothesis (H0) was that solar irradiation derived from the two surface models had the same mean rank, and the alternative hypothesis (H1) was that the mean ranks of the irradiation values were different at the $\mathrm{p}<0.05$ level. Accordingly, Friedman's ANOVA and the Wilcoxon paired test were applied in the hypothesis testing phase, combined with a Bonferroni correction (Zar, 1999). In the validation process of the building geometry, we calculated Cohen's Kappa (Kappa Index of Agreement, KIA; Cohen, 1960). KIA is a measure of association, requires nominal values, and indicates whether the agreement occurs by chance (ranges are between 0 and 1; 0 indicates agreement by chance, while 1 is total agreement; Rosenfeld and Fitzpatrick-Lins, 1986). We compared the building contours based on GPS measurements and those that were derived from the 3D point cloud. Heights and area surfaces of the sample building were compared with the Wilcoxon paired test, and RMSE values were calculated. We evaluated statistical tests with $\mathrm{p}$ values $(\mathrm{p}<0.05)$, and also with effect size as a standardized measure of the difference between groups (Cohen, 1992). 


\section{Results}

\subsection{Roof extraction from the LiDAR point cloud and the DSMS}

The validation process demonstrated that the automatic detection of buildings was successful, and the KIA was 0.94. Considering that field surveys provided data for the contours of the buildings and not the ground projection of the roofs, a smaller proportion of the errors can be attributed to eaves (i.e. the difference between the outer walls and the roofs).

The difference between LiDAR data and the measured values of building heights was $0.31 \mathrm{~m}$ on average (including a measuring uncertainty of $\pm 6 \mathrm{~cm}$ of the Leica Disto device), and was controlled for roof types (Table 1). Although the Wilcoxon-test between the field data and the ones from the LiDAR survey showed a significant difference $(\mathrm{p}<0.05)$, the effect size was very weak $(\mathrm{r}=0.04)$, showing the slight (ignorable) difference in data ranges.

\# Table 1 approximately here

There were four variations of the extracted roofs and all of them showed similar characteristics. Roof planes derived from the LiDAR point cloud with Terrascan showed a more realistic picture compared to the DSM derived from the aerial images. However, in accordance with our aims it was an important question whether the segmentation of LiDAR DSM (SDSM) can be used as an alternative in the analysis. If this is the case, then it worth adopting the photogrammetric approach. The DSM result was not as impressive as the outcome of the processing in the CAD environment (with Terrascan). Although edges were rugged (see Fig. 3), we supposed that the segmented roof planes can carry enough information to calculate solar irradiation data.

We detected a different number of roof planes which could be considered as suitable for installing solar panels (Table 2). The differences originated from the fact that various techniques detected different numbers of surfaces as roofs; furthermore, due to the varying characteristics (aspect and slope) of the identified roof planes, suitable items had varying extents (Table 3). Some roof planes were not detected when we applied DSMs. Edges produced with segmentation were not straight; this was the consequence of the approach based on raster's resolution (i.e. pixels). Considering the heterogeneity of DSMs and the orthophotos, the result was acceptable and showed the required surfaces - with a controllable amount of errors.

\# Table 2 approximately here \# Table 3 approximately here 
Given that generally not every object had a pair in the various solutions found in the campus area, we

\# Fig. 3. approximately here

\subsection{Solar irradiation}

The analysis of the hostel building's roof planes explored the efficiency of the different techniques which can be used to delineate roof planes. All models yielded a roof area of between 691 and $862 \mathrm{~m}^{2}$ and the annual insolation was between 903 and 1127 MWh. Both Friedman's ANOVA and its post hoc test, the Wilcoxon test with Bonferroni corrected $\mathrm{p}$ values, showed that there were no significant differences between the four models (Table 4). Consequently, in the next steps of the analysis only the most accurate LiDAR model and the segmented PDSM model were used.

\#Table 4 approximately here

Only slight differences were observed when we compared the incoming solar energy using the blueprints of the building and the roof planes extracted from the LiDAR point cloud. The incoming solar radiation on the total roof area provided by the automated method was $5.8 \%$ higher compared to the manual method; however, the calculated PV areas were larger in case of the manual method (Table $5)$.

There were 739 PV panels calculated with the traditional approach, using the blueprints, and 671 panels in the case of the roof planes extracted from LPC and using the developed ArcGIS extension (Fig. 4). Omitting the northern roof planes, the number of PV panels changed to 660 and 553, respectively; furthermore, the incoming solar energy is reduced by $14.9 \%$ in the case of the automatic method and $9.6 \%$ with the manual method.

\#Table 5 approximately here

\#Fig. 4 approximately here

The solar irradiation of the campus area (13 buildings, Fig. 5), regarding the suitable roof planes, was $13353 \mathrm{MWh} /$ year based on the LiDAR point cloud (LPC), while segmented DSM derived from the drone survey (PDSM) resulted in $12059 \mathrm{MWh} /$ year incoming solar irradiation. However, the 
difference, regarding the Wilcoxon test was not significant, and the effect size can be considered weak $(\mathrm{z}=1.36, \mathrm{~N}=26, \mathrm{p}=0.19, \mathrm{r}=0.26)$.

\#Fig. 5 approximately here

\section{Discussion}

In recent years, geoinformation (GI) science has had an exponentially growing relevance in all areas of science and practice. Surveys of possible surfaces for solar panels can be accelerated by GI technologies, too (Izquierdo et al., 2013). The present study introduces a method of applying remotely sensed data in the automated registration of roof planes on which solar panels can be installed. There have been several successful attempts using the LiDAR or the photogrammetric approach in roof identification, but small format cameras were not compared with other solutions (e.g. Jakubiecz and Reinhart, 2013; Lukac et al., 2013; Lukac et al., 2014). However, fewer results have been reported with the photogrammetric approach. Frank and Mucsi (2014) applied medium format aerial photographs for a similar survey and found that it can be a cost effective approach, but the results were not validated.

The differences in roof heights were acceptable, because the DSM resolution and the interpolation itself can alter the "raw" data of the point cloud (as the greatest error was experienced with complex shaped roofs). However, according to Nguyen et al., (2014), this vertical error does not bias solar energy income as much as horizontal inaccuracies.

\subsection{Drone surveys as alternative tools for determining solar potential}

Drones can survey only smaller areas and can raise problems according to property rights, but the results can be compared to the results of large format cameras or LiDAR systems. The application of drones in surveying does not have a long history. In recent years, we have witnessed a rapid development of drones and similarly to the LiDAR technique, their availability has become easier as has the accompanying software environment. Only less than a decade ago, it was unimaginable to use traditional cameras for photogrammetric purposes, and now we have successfully applied a GoPro action camera with a wide-angle lens. Furthermore, due to perspective distortion, photogrammetry presented a significant disadvantage: the projected area was only free of distortion at the nadir position. Objects, especially the top of high buildings and basements seem to shift; consequently, tops of buildings are not in their real positions. Barizetti et al., (2014) also found that with the large numbers of photos taken in drone surveys we can obtain true orthophotos, without perspective distortion. DSMs generated from aerial photos carry the most important information, the height, which serves as the basis of the calculation of aspect and slope of the pixels. Consequently, both orthophotos and DSMs carry important spatial information (in the right position), and consequently both can be involved in the analysis. Point cloud processing can be regarded an accurate technique in roof 
registration but segmentation performed well in several studies of feature extraction. Belgiu and Dragut (2014) applied multiresolution segmentation to extract buildings from WorldView-2 images and proved that imperfections of the classification can be filtered out and a high level of thematic accuracy can be ensured. Furthermore, Kampouraki et al., (2008) also found that multiresolution segmentation can perform well in urban environment with the concept of applying different scales combined with hierarchical connections between the objects of scale levels. In our study, the drone survey and the segmentation performed well and did not show a significant difference from the LiDAR-based results, which is considered the best possible solution. Although the differences were small, we have to allow for errors arising from the inaccuracies of the processing. However, all models have errors (even LiDAR surveys contain errors), so we must always balance the costs and targeted aims. Maybe a drone survey will not provide the best solution but, according to our results, it can provide an efficient tool that can be an alternative to LiDAR based analysis.

\subsection{Cost benefit issues}

Our study proved that data extracted from aerial surveys can perform as well as individual studies based on blueprints. However, the aims can be different: developing a new calculation method (research studies) or surveying the solar potential for a city or part of a city (feasibility studies). Accordingly, we summarized the advantages and disadvantages of the different techniques with the predicted cost-benefit issues (Table 6). Costs cannot be predicted because, especially in the case of LiDAR surveys, they are highly dependent on the distance between the airport and the target area and the extent of the target area: the larger the area, the more favorable the price per $\mathrm{km}^{2}$, and, the lower the price in terms of the number of houses. LiDAR systems require a high performance IT infrastructure for processing: the aeroplane, sensors, computers, software and also skilled personnel (pilot, geoinformation systems expert for the point cloud processing); furthermore, the raw 3D point cloud in itself is not sufficient for the user, it is essential to pay for the data extraction, too. This complexity at each step explains the high price of this kind of data capture.

A specific characteristic of the LiDAR surveys is that the return on the money invested is indirect; therefore, these surveys should be carried out under the auspices of funded projects with research aims (e.g. Agugiaro et al., 2012; Jochem et al., 2009); however, there are some exceptions (e.g. the Vienna solar income database was partially funded by the green energy industry, and the aim was to realize the solar potential of the city). A further aim is to show the results to the public through a web application (Brumen et al., 2014).

A drone survey, on the other hand, is significantly cheaper and can be funded by a smaller local authority or a firm. Although data processing also requires true orthopotos without perspective distortion (Barizetti et al., 2014), software and expertise, the prerequisites are cheaper. In our study this survey was conducted in the university campus with 13 buildings (although the density of the buildings was not as high as in residential areas) and provided a comprehensive basis for the 
calculation of the solar energy income. Considering the errors, we can consider the results acceptable,

\#Table 6 approximately here

\section{Conclusions}

LiDAR is a relatively new and popular technology for data collection. It provides the most accurate representation of the surface, due to its high sampling density. However, the technology is expensive and needs expensive infrastructure and expertise to evaluate the raw data. Drones are becoming widespread in all areas of life. Combining aerial imaging acquired with drones, we can produce orthophotos and digital surface models. In this study, we compared a LiDAR and a drone survey in terms of their efficiency in detecting roofs.

The traditional approach can be regarded as the most authentic method, but cannot be applied over large areas. The results reflected the fact that LiDAR is the best solution for extracting buildings or roofs, but processing DSMs combined with segmentation techniques can also be an effective tool. Our results showed that in smaller areas, with the appropriate resolution, we can obtain DSMs which are suitable for analysis. Obviously, the data quality and reliability lags behind LiDAR; however, the costbenefit ratio is significantly better.

\section{Acknowledgement}

The work is supported by the University of Debrecen (RH/751/2015) and TÁMOP-4.2.2.A11/1/KONV-2012-0041 and SROP-4.2.2.B-15/1/KONV-2015-0001 projects. The project is cofinanced by the European Union and the European Social Fund.

\section{References}

Agugiaro, G., Nex, F., Remondino, F., de Filippi, R., Droghetti, S., Furlanello, C., 2012. Solar radiation estimation on building roofs and web based solar cadastre. ISPRS Ann. Photogramm. Remote Sens. Spatial Infor. Sci. I-2.

Alexander, C., Skith-Voysey, S., Jarvis, C., Tansey, K., 2009. Integrating building footprints and LiDAR elevation data to classify roof structures and visualise buildings. Computers, Comput. Environ. Urban Syst. 33, 285-292.

Amhar, F., Jansa, J., Ries, C., 1998. The generation of the true orthophotos using a 3D building model in conjunction with a conventional DTM. Int. Arch. Photogramm. Remote Sens. 32, 16-22. 
Baltsavias, E., 1999. A comparison between photogrammetry and laser scanning. Int. Arch.

Photogramm. Remote Sens. 54, 83-94.

Barrizzetti, L., Brumana, R., Oreni, D., Previtali, M., Roncoroni, F., 2014. True-orthophoto generation from UAV images: implementation of a combined photogrammetric and computer vision approach. Int. Arch. Photogramm. Remote Sens. II-5, 57-63.

Belgiu, M., Dragut, L., 2014. Comparing supervised and unsupervised multiresolution segmentation approaches for extracting buildings from very high resolution imagery. Int. Arch. Photogramm. Remote Sens. 96, 67-75.

Bin, X., Fangfei, L., Keshu, Z., Zongjian, L., 2008. Laser footprint size and pointing precision analysis for LiDAR systems. Int. Arch. Photogramm. Remote Sens. 37(B1), 331-335.

Blascke, T., 2010. Object based image analysis for remote sensing. Int. Arch. Photogramm. Remote Sens., 65, 2-16.

Boehner, J., Antonic, O., 2009. Land Surface Parameters Specific to Topo-Climatology, in Hengl, T. and Reuter, H.I. (Eds.), Geomorphometry - Concepts, Software, Applications, Elsevier, Amsterdam, pp. 195-226.

Chassereau, J.E., Bell, J.M., Torres, R., 2011. A comparison of GPS and LiDAR salt marsh DEMs. Earth Surf. Proc. Land. 36, 1770-1775.

Cekada, M.T., Crosilla, F., Fras, K., (2010) Theoretical LiDAR point density for topographic mapping in the largest scales. Geodetsky Vestnik 54, 403-416.

Cohen, J., 1960. A coefficient of agreement for nominal scales. Educ. Psychol. Meas. 20, 37-46.

Cohen, J., 1992. Statistical power analysis. Curr. Dir. Psychol. Sci. 1, 98-101.

Demir, N., Poli, D., Baltsavias, E., 2008. Extraction of buildings and trees using images and LiDAR data. Int. Arch. Photogramm. Remote Sens. 37, Part B4, 313-318.

Dorninger, P., Székely, B., Zámolyi, A., Roncat, A., 2014. Automated Detection and Interpretation of Geomorphic Features in LiDAR Point Clouds. Österreichische Zeitschift Für Vermessung Und Geoinformation 99, 60-69.

European Commission, 2014. Horizon 2020 in brief, The EU Framework Programme for Research and Innovation, European Union, Publications Office, 35 p.

Farkas, I., 2010. Domestic possibilities of solar energy use (in Hungarian). Magyar Tudomány 171, 937-946.

Frank, M., Mucsi, L., 2014. Automated Creation of a 3D Surface Model and Calculation of the Solar Energy Income for a Test Site Situated in City of Szeged (in Hungarian). Geodézia és Kartográfia 66, 16-22.

Früh, C., Zakhor, A., 2003. Contracting 3D city models by merging aerial and ground views. IEEE Comput. Graph. Appl. Mag., Special issue: 3D Reconstruction and Visualization, 52-61. 
Gatziolis, D., Andersen, H-E., 2008. A Guide to LIDAR Data Acquisition and Processing for the Forests of the Pacific Northwest, USDA Forest Service, Pacific Northwest Research Station, General Technical Report PNW-GTR-768, http://www.fs.fed.us/pnw/pubs/pnw_gtr768.pdf

Ghuffar, S., Székely, B., Roncat, A., Pfeifer, N., 2013. Landslide displacement monitoring using 3D Range Flow on airborne and terrestrial LiDAR data. Remote Sens. 5, 2720-2745.

Heiskanen, E., Nissila, H., Lovio, R., 2015. Demonstration buildings as protected spaces for clean energy solutions - the case of solar building integration in Finland. J. Clean. Prod. doi:10.1016/j.jclepro.2015.04.090

Hengl, T., Grohmann, C.H., Bivand, R.S., Conrad, O., Lobo, A., 2009. SAGA vs GRASS: A Comparative Analysis of the Two Open Source Desktop GIS for the Automated Analysis of Elevation Data, Proc. Geomorphometry 2009, Zurich, Switzerland, pp. 22-27.

Hofierka, J., Kaňuk, J., 2009. Assessment of photovoltaic potential in urban areas using open-source solar radiation tools. Renew. Energ. 34, 2206-2214.

Hofierka, J., Šuri, M., 2002. The solar radiation model for open source GIS: implementation and application, Proc. Open-source GIS-GRASS users conference, Trento, Italy, pp. 1-19.

Iqbal, M., 1983. An Introduction to Solar radiation, Academic Press Canada, Ontario

Izquierdo, S., Rodrigues, M., Fueyo, N., 2008. A method for estimating the geographical distribution of the available roof surface area for large-scale photovoltaic energy-potential evaluations. Sol. Energ. 82, 929-939.

Jakubiecz, J.A., Reinhart, C.F., 2013. A method for predicting city-wide electricity gains from photovoltaic panels based on LiDAR and GIS data combined with hourly Daysim simulations. Sol. Energ. 93, 127-143.

Jochem, A., Höfle, B., Rutzinger, M., Pfefier, N., 2009. Automatic Roof Plane Detection and Analysis in Airborne LiDAR Point Clouds for Solar Potential Assessment. Sensors 9, 5241-5262.

Kampouraki, M., Wood, G.A., Brewer, T.R., 2008. Opportunities and limitations of object-based image analysis for detecting urban impervious and vegetated surfaces using true-colour aerial photography, in Blaschke, T., Lang, S., Hay, G.J. (Eds), Object-Based Image Analysis, Springer, Berlin-Heidelberg, pp. 555-569.

Kassner, R., Koppe, W., Schüttenberg, T., Bareth, G., 2008. Analysis of the solar potential of roofs by using official LiDAR data. Int. Arch. Photogramm. Remote Sens. 37 Part B4, 399-404.

Korpela, I., Hovi, A., Morsdorf, F., 2012. Understory trees in airborne LiDAR data - Selective mapping due to transmission losses and echo-triggering mechanisms. Remote Sens. Environ. $119,92-104$.

Kozma, G., Molnár, E., Czimre, K., Pénzes, J., 2013. Geographical aspect diffusion of passive houses. Int. Rev. Appl. Sci. Eng. 4, 151-156. 
Kumar M., Singh, R.K., Raju, P.L.N., Krishnamurthy, Y.V.N., 2014. Road Network Extraction from High Resolution Multispectral Satellite Imagery Based on Object Oriented Techniques. ISPRS Ann. Photogramm. Remote Sens. Spatial Infor. Sci. II-8, 107-110.

Lázár, I., 2011. Effects of climate change on renewable energy sources (in Hungarian), in Szabó V, Fazekas I. (Eds.), Környezettudatos energiatermelés- és felhasználás, MTA DAB Megújuló Energetikai Munkabizottság, Debrecen, 2011, pp. 92-98.

Lewis, N.S., 2007. Towards cost-effective solar energy use. Science 315, 798-801.

Lin, X., Zhang, J., 2014. Segmentation-Based Filtering of Airborne LiDAR Point Clouds by Progressive Densification of Terrain Segments. Remote Sens. 6, 1294-1326.

Liu, X., 2008. Airborne LiDAR for DEM generation: some critical issues. Prog. Phys. Geog. 32, $31-$ 49.

Lukac, N., Seme, S., Zlaus, D., Stumberger, G., Zalik, B., 2014. Buildings roofs photovoltaic potential assessment based on LiDAR (Light Detection And Ranging) data. Energy 66 (2014) 598-609.

Lukac, N., Zlaus, D., Seme, S., Zalik, B., Stumberger, G., 2013. Rating of roofs' surfaces regarding their solar potential and suitability for PV systems, based on LiDAR data. Applied. Energ. 102, 803-812.

May, C.N., Toth, C.K., 2007. Point positioning accuracy of airborne LiDAR systems: a rigorous analysis. Int. Arch. Photogramm. Remote Sens. 36(3/W49B), 107-111.

Mongus, D., Lukac, N., Zalik, B., 2014. Ground and building extraction from LiDAR data based on differential morphological profiles and locally fitted surfaces, Int. Arch. Photogramm. Remote Sens. 93, 145-156.

Mücke, W., Deák, B., Schroiff, A., Hollaus, M., Pfeifer, N., 2013. Detection of fallen trees in forested areas using small footprint airborne laser scanning data. Can. J. Remote Sens. 39, 32-40.

Nagyváradi, L., Gyenizse, P., Szebényi, A., 2011. Monitoring the changes of a suburban settlement by remote sensing. Acta Geographica Debrecina Landscape Env. 5, 76-83.

Nex, F., Remondino, F., Agugiaro, G., de Filippi, R., Poletti, M., Furlanello, C., Menegon, S., Dallago, G., Fontanari, S., 2013. 3D solarweb: A solar cadaster in the Italian alpine landscape. Int. Arch. Photogramm. Remote Sens. XL-7/W2, 173-178.

Nguyen, H.T., Pearce, J.M., Harrap, R., Barber, G., 2012. The Application of LiDAR to Assessment of Rooftop Solar Photovoltaic Deployment Potential in a Municipal District Unit. Sensors, 12, 4534-4558.

Paparoditis, N., Polidori, L., 2004. Overview of digital surface models, In Egels, Y and Kasser, M. (Eds.), Digital Photogrammetry, Taylor and Francis, London, pp. 159-163.

Paulescu, M., Paulescu, E., Gravila, P., Badescu, V., 2013. Weather modeling and forecasting of PV systems operation, Springer, London

Priestnall, G., Jaafar, J., Duncan, A., 2000. Extracting urban features from LiDAR digital surface models. Comput. Env. Urban Syst. 24, 31, 65-78. 
Protic, D., Kilibarda, M., Vucetic, I., Nestorov, I., 2002. 3D roof modelling for accurate assessment of solar potential, Proc. EuroSun 2002 Int. Conference, Bologna, Italy, 5 p.

Quazi, A., Fayaz, H., Wadi, A., Raj, R.G., Rahim, N.A., Khan, W.A., 2015. The artificial neural network for solar radiation prediction and designing solar systems: a systematic literature review. J. Clean. Prod. 104, 1-12.

Reindl, D.T., Beckman, W.A., Duffie, J.A., 1990. Evaluation of hourly pitched surface radiation models. Solar Energy 45, 9-17.

Rosenfeld, G.H., Fitzpatrick-Lins, K., 1986. A Coefficient of Agreement as a Measure of Thematic Classification Accuracy. Photogramm. Eng. Remote Sens. 52, 223-227.

Rouse, J.W., Haas, R.H., Schell, J.A., Deering, D.W., 1973. Monitoring vegetation systems in the Great Plains with ERTS, Third ERTS Symposium, NASA SP-351, Vol. 1. NASA, Washington, DC, pp. 309-317.

Shan, J., Toth, C.K., 2008. Topographic Laser Scanning and Ranging: Principles and Processing, CRC Press, Boca Raton

Shao, P., Yang, G., Niu, X., Zhang, X., Zhan, F., Tang, T., 2014. Information Extraction of HighResolution Remotely Sensed Image Based on Multiresolution Segmentation. Sustainability 6, $5300-5310$.

Shortis, M.R., Johnston, G.H.G., Pottler, K., Lüpfert, E., 2008. Photogrammetric analysis of solar collectors. Int. Arch. Photogramm. Remote Sens. 37 Part B5, 81-88.

Smyth, M., 2012. Solar photovoltaic installations in American and European winemaking facilities. J. Clean. Prod. 31, 22-29.

Stevanovic, S., 2013. Optimization of passive solar design strategies: A review. Renew. Sust. Energ. Rev. 25, 177-196.

Weih, R.C., Riggan, N.D., 2010. Object-Based Classification vs. Pixel-Based Classification: Comparative Importance of Multi-Resolution Imagery. Int. Arch. Photogramm. Remote Sens. (GEOBIA 2010), XXXVIII-4/C7

Yu, B., Liu, H., Wu, J., Hu, Y., Zhang, L., 2010. Automated derivation of urban building density information using airborne LIDAR data and object-based method, Landscape Urban Plan. 98, 210-219.

Zar, J.H., 1999. Biostatistical Analysis. Prentice Hall, New Jersey,

Zhou, Q., Neumann, U., 2013. Complete residential urban area reconstruction from dense aerial LiDAR point clouds. Graph. Models 75, 118-125.

Zlinszky, A., Schroiff, A., Kania, A., Deák, B., Mücke, W., Vári, Á., Székely, B., Pfeifer, N., 2014. Categorizing Grassland Vegetation with Full-Waveform Airborne Laser Scanning: A Feasibility Study for Detecting Natura 2000 Habitat Types. Remote Sens. 6, 8056-8087.

\section{Web references}


https://www.maxmax.com/RemoteSensingcamerasi.htm, LDP-LLC Ltd.

1 https://www.terrasolid.com/download/tscan.pdf, Terrasolid, Ltd., Terra Scan User's Guide, 
Table 1. Difference of roof heights (relative heights of LiDAR surface subtracted from measurements)

\begin{tabular}{lllll}
\hline Roof type & $\begin{array}{l}\text { Lower } \\
\text { quartile }\end{array}$ & Median & $\begin{array}{l}\text { Upper } \\
\text { quartile }\end{array}$ & RMSE \\
\hline Flat & -0.01 & 0.17 & 0.45 & 0.30 \\
Shed & -0.18 & 0.03 & 0.20 & 0.31 \\
Gable & -0.02 & 0.11 & 0.29 & 0.34 \\
Combination & -0.25 & 0.01 & 0.23 & 0.43 \\
\hline
\end{tabular}


Table 2. Number and area of roof planes in the campus area

1

2

3

4

5

6

7

8

9

10

11

12

13

14

15

16

17

18

19

20

21

22

23

24

25

26

27

28

29

30

31

32

33

34

35

36

37

38

39

40

41

42

43

44

45

46

47

48

49

50

51

52

53

54

55

56

57

58

59

60

61

62

63

64

65

\begin{tabular}{lll}
\hline Method & $\begin{array}{l}\text { Number of detected } \\
\text { planes }\end{array}$ & $\begin{array}{l}\text { Sum of the area } \\
{\left[\mathrm{m}^{2}\right]}\end{array}$ \\
\hline LPC & 68 & 5432 \\
SDSM & 79 & 4893 \\
PDSM & 78 & 5197 \\
OPDSM & 52 & 5239 \\
\hline
\end{tabular}


Table 3 Statistical characteristics of roof planes of the hostel building, considering the four calculation methods ( $\mathrm{N}=4$ according to the four methods; unit: $\mathrm{m}^{2}$ )

\begin{tabular}{lrrrrr}
\hline & \multicolumn{5}{c}{ Roof plane IDs } \\
\cline { 2 - 6 } & 16 & 20 & 23 & 24 & 31 \\
\hline Minimum & 150.76 & 78.17 & 244.30 & 76.44 & 30.60 \\
Maximum & 182.54 & 100.47 & 284.89 & 96.97 & 70.32 \\
Mean & 160.19 & 90.53 & 257.15 & 88.12 & 52.08 \\
Standard error & 7.49 & 5.35 & 9.45 & 5.21 & 9.48 \\
Standard deviation & 14.97 & 10.70 & 18.90 & 10.43 & 18.97 \\
Median & 153.72 & 91.74 & 249.69 & 89.53 & 53.70 \\
25 percentile & 151.45 & 79.90 & 244.75 & 77.88 & 33.42 \\
75 percentile & 175.39 & 99.95 & 277.00 & 96.94 & 69.13 \\
Coefficient of variation & 9.35 & 11.82 & 7.35 & 11.83 & 36.42 \\
\hline
\end{tabular}


Table 4. Comparison of the incoming solar energy on the roof planes of the hostel building (p values, Wilcoxon test with Bonferroni correction; (LPC: LiDAR point cloud processing; SDSM: DSM from LiDAR + segmentation; PDSM: DSM from aerial photographs + segmentation; OPDSM: DSM from aerial photographs combined with orthophoto + segmentation)

$$
\text { LPC SDSM PDSM }
$$

\begin{tabular}{lrrrr}
\hline & LPC & SDSM & \multicolumn{2}{c}{ PDSM } \\
\hline SDSM & 0.5455 & & \\
PDSM & 0.9091 & 1 & \\
OPDSM & 1 & 1 & 1 \\
\hline
\end{tabular}


Table 5. Incoming solar energy on the hostel building's roof planes (Incoming solar irradiation [kWh]; Roof plane IDs correspond to Fig. 4)

\begin{tabular}{llllll}
\hline Roof & Roof & Calculated & Surface & $\begin{array}{l}\text { Calculated } \\
\text { surface }\end{array}$ & $\begin{array}{l}\text { Surface for PV } \\
\text { panels except }\end{array}$ \\
plane ID & $\begin{array}{l}\text { plane } \\
\text { surface }\end{array}$ & $\begin{array}{l}\text { roof plane } \\
\text { surface }\end{array}$ & por PV & $\begin{array}{l}\text { panels } \\
\text { for PV } \\
\text { panels }\end{array}$ & $\begin{array}{l}\text { northern } \\
\text { directions }\end{array}$
\end{tabular}

Calculated surface for PV panels except northern directions

\begin{tabular}{|c|c|c|c|c|c|c|}
\hline 0 & 462203 & 438925 & 245800 & 256056 & 245800 & 256056 \\
\hline 1 & & 6622 & & 0 & & 0 \\
\hline 2 & & 7839 & & 0 & & 0 \\
\hline 3 & 163404 & 109964 & 79207 & 33421 & 0 & 0 \\
\hline 4 & 27739 & 25715 & 11044 & 7305 & 0 & 0 \\
\hline 5 & 197275 & 54191 & 32885 & 19126 & 0 & 0 \\
\hline 6 & 21756 & 26707 & 7650 & 7586 & 7650 & 7586 \\
\hline 7 & 22204 & 24842 & 0 & 5565 & 0 & 0 \\
\hline 8 & 74579 & 76779 & 26940 & 32458 & 26940 & 32458 \\
\hline 9 & 117252 & 82262 & 37154 & 29033 & 37154 & 29033 \\
\hline 10 & 30465 & 36849 & 2055 & 8254 & 2055 & 8254 \\
\hline 11 & 428893 & 448378 & 228987 & 290448 & 228987 & 290448 \\
\hline 12 & 62024 & 76814 & 21623 & 32472 & 21623 & 32472 \\
\hline 13 & 158239 & 146923 & 72752 & 63890 & 72752 & 63890 \\
\hline 14 & 127699 & 122964 & 56923 & 61851 & 0 & 0 \\
\hline 15 & 275257 & 284305 & 142410 & 176715 & 142410 & 176715 \\
\hline 16 & 37727 & 76814 & 7437 & 32472 & 7437 & 32472 \\
\hline 17 & 276441 & 275325 & 139278 & 173186 & 139278 & 173186 \\
\hline 18 & 158103 & 152502 & 73845 & 73886 & 73845 & 73886 \\
\hline 19 & 68755 & 76779 & 25157 & 32458 & 25157 & 32458 \\
\hline $\begin{array}{l}\text { Total } \\
\text { Ratio } 1\end{array}$ & 2710015 & 2551500 & 1211148 & 1336183 & 1031089 & 1208917 \\
\hline $\begin{array}{l}\text { [\%] } \\
\text { Ratio }^{2}\end{array}$ & 100 & 94.2 & 100 & 110.3 & 100 & 117.2 \\
\hline [\%] & 100 & 94.2 & 44.7 & 49.3 & 38.0 & 44.6 \\
\hline
\end{tabular}


Table 6. Comparison of different surveying techniques and possible returns in terms of solar panels

\begin{tabular}{llll}
\hline & $\begin{array}{l}\text { Calculations based on } \\
\text { blueprints }\end{array}$ & Drone survey & LiDAR survey \\
\hline area/object & usually 1 house & $\sim 1-5 \mathrm{~km}^{2} /$ day & $\sim 800-1000 \mathrm{~km}^{2} / \mathrm{day}$ \\
absolute cost & low & low & High \\
relative cost & high & low & Low \\
(price/building) & & & \\
cost/benefit & can be financed by a & can be financed by a & should be financed by \\
& single household & local authority or firm & a project fund \\
return & soon & soon & there is no direct \\
& & & return \\
IT infrastructure & low & medium & high \\
requirement & & high & high \\
HR expertise & medium & & \\
requirement & & & \\
\hline
\end{tabular}


Figure captions

Fig. 1. Study sites of the roof plane analysis

Fig. 2. Flowchart of the point cloud and digital surface model analysis, and the extraction of roof planes being appropriate for solar panel installation

Fig. 3. Roof planes of the hostel building extracted with different methods (a: LPC, b: SDSM, c: PDSM, d: OPDSM)

Fig. 4. Placement plan of PV panels on the hostel building (a: IDs of roof planes) with the automated method (b) and the manual method (c)

Fig. 5. Roof planes suitable for PV panels predicted with LiDAR point cloud processing (a, LPC) and photogrammetric processing of the images of the drone survey (b, PDSM) 


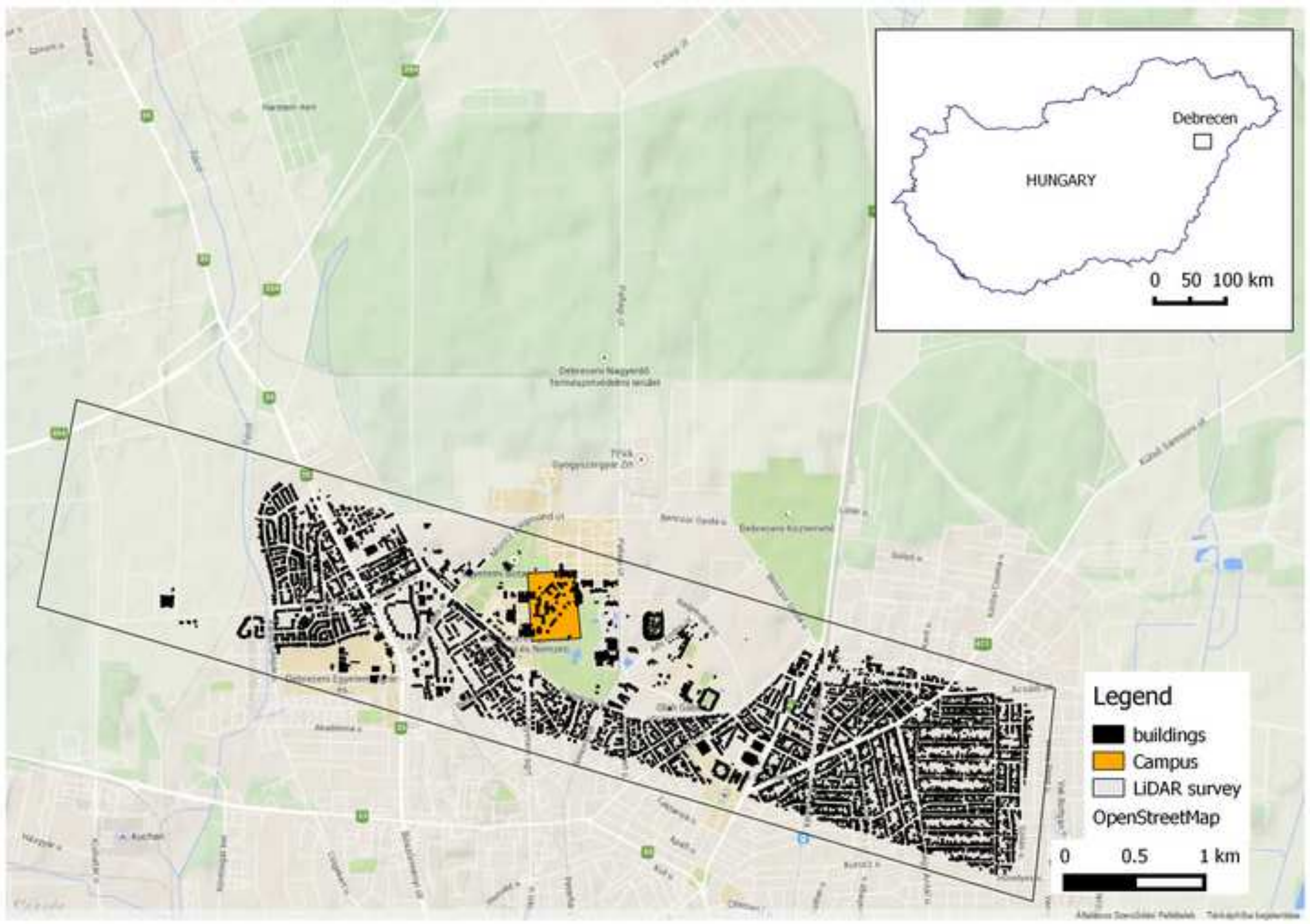


Click here to download high resolution image

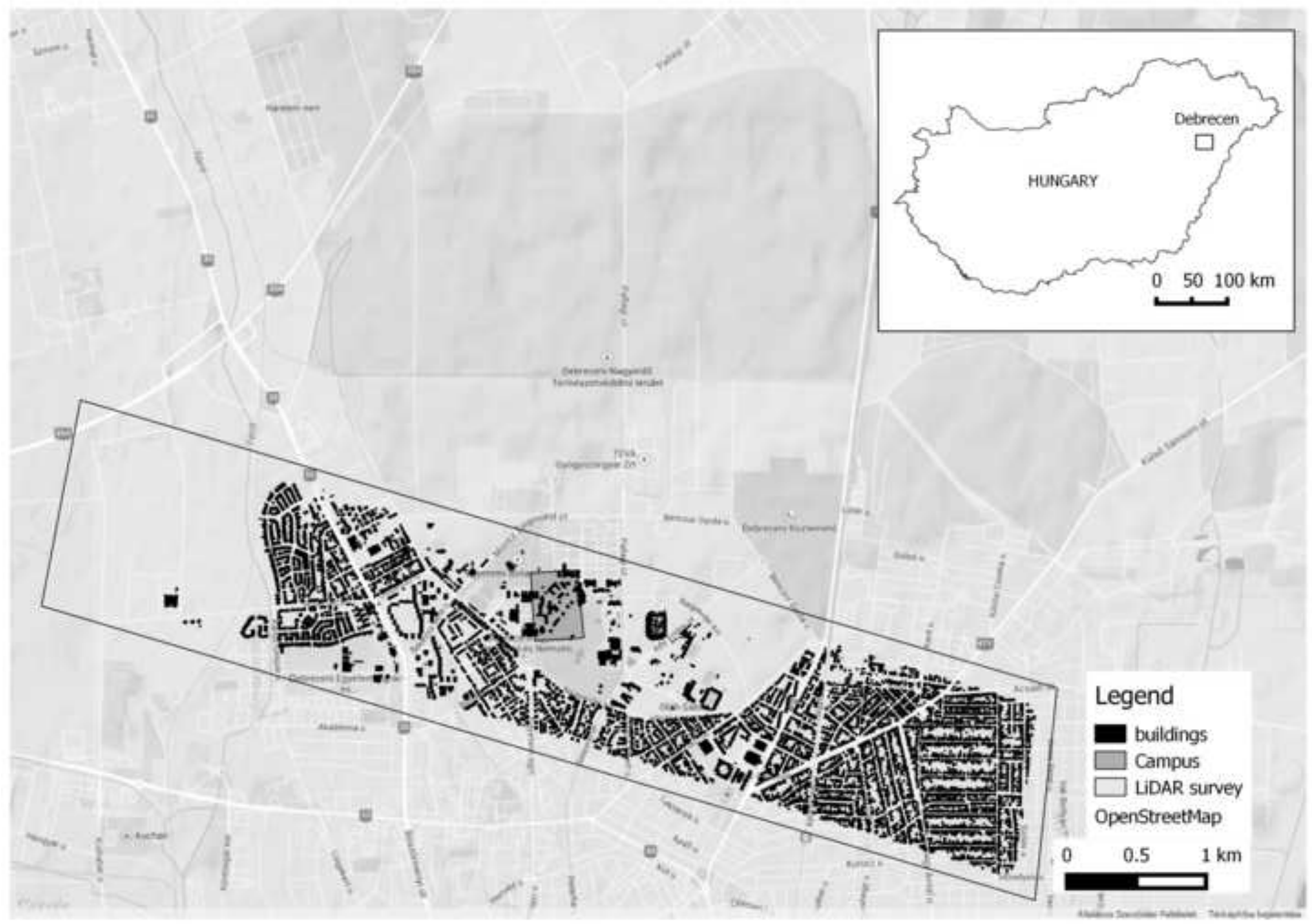




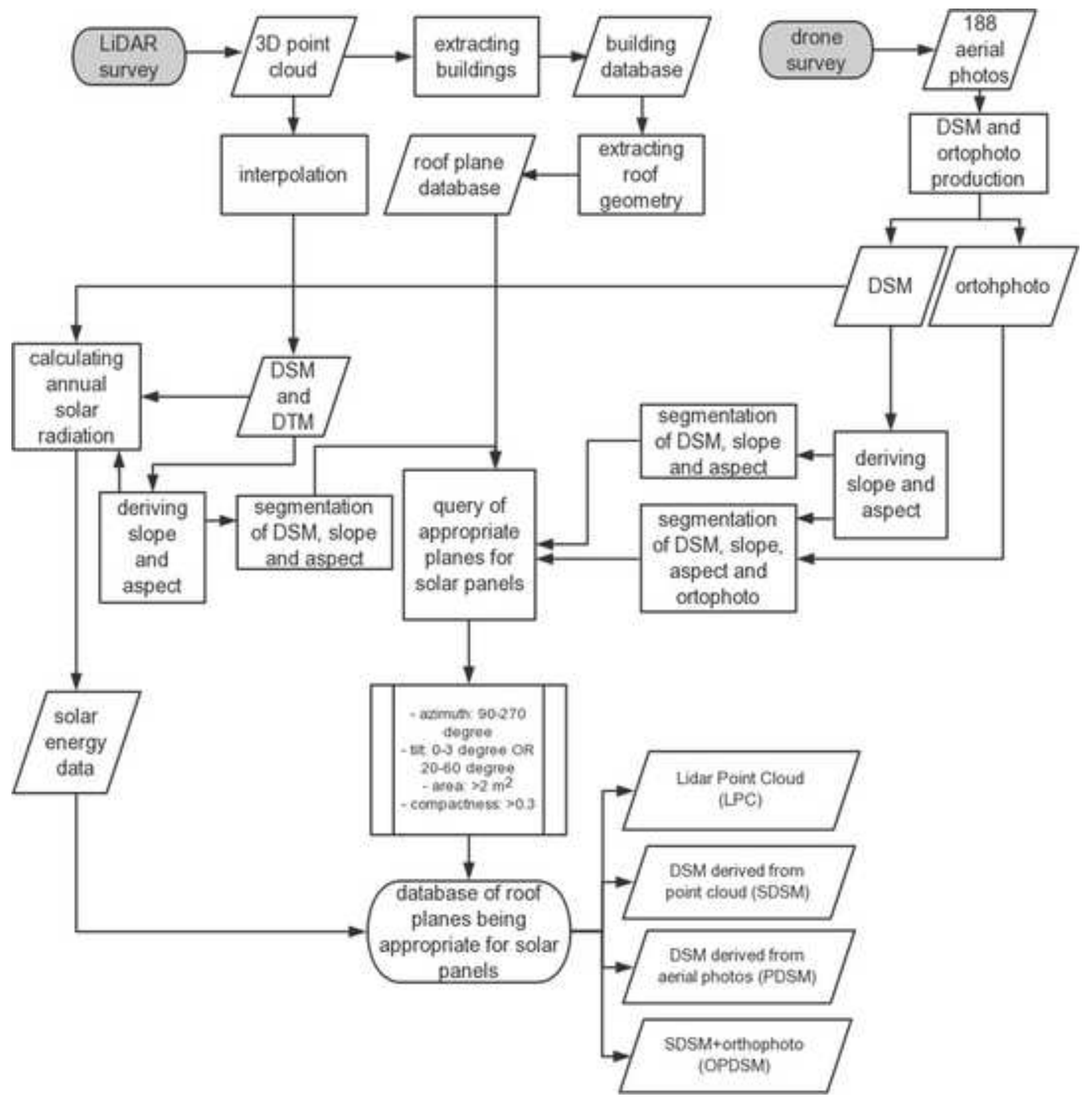


Figure 3 online
Click here to download high resolution image

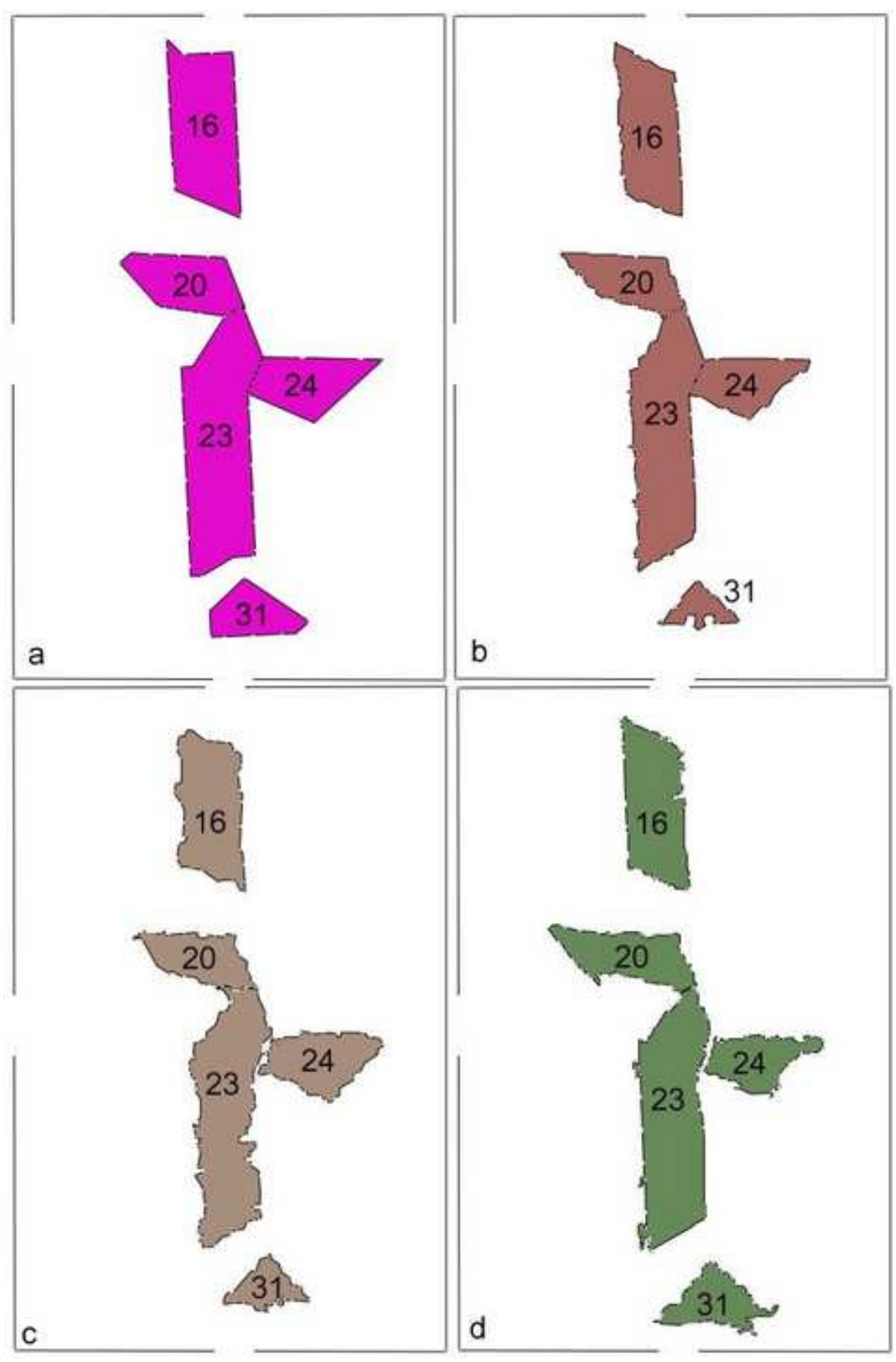


Click here to download high resolution image

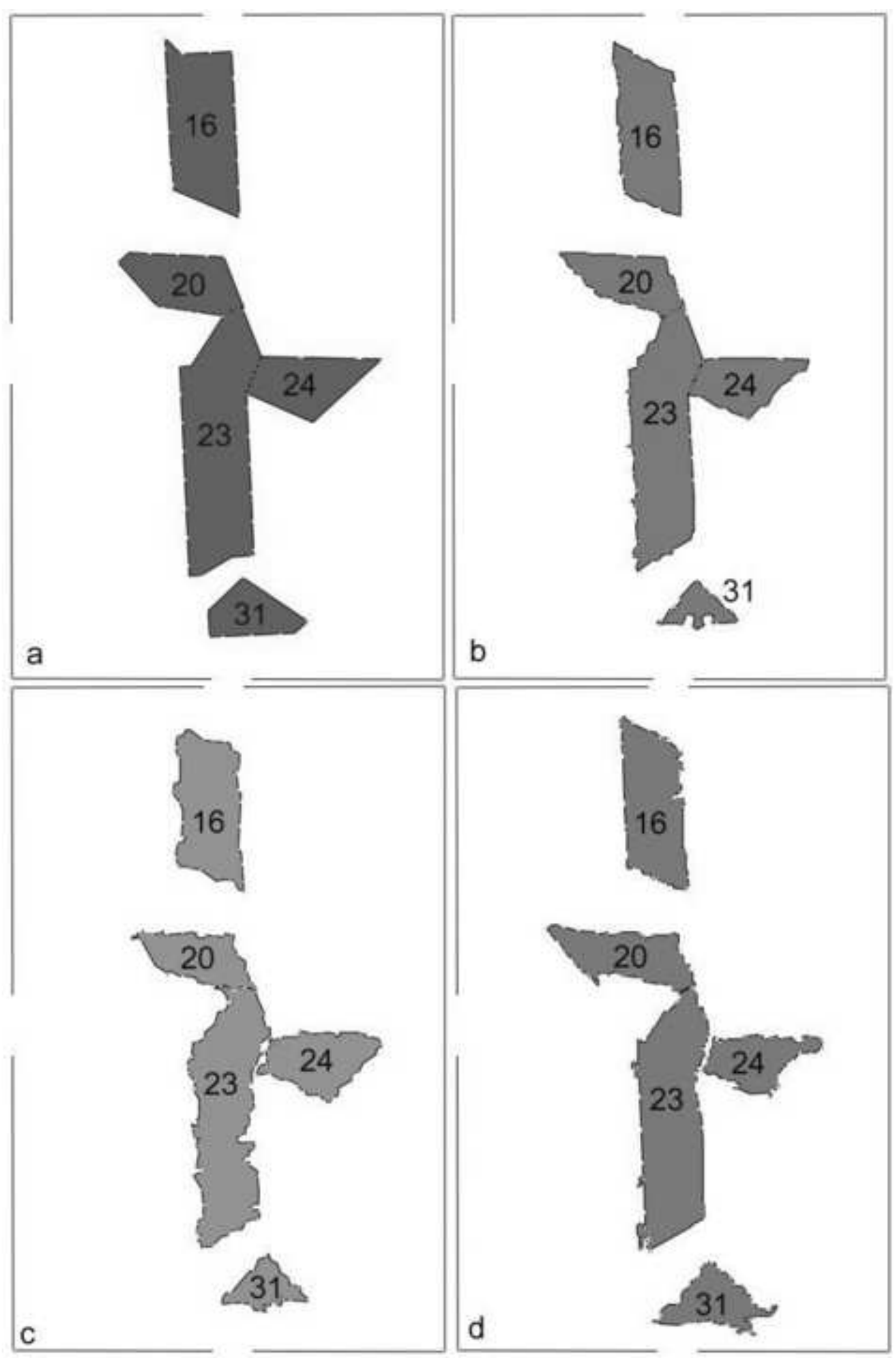



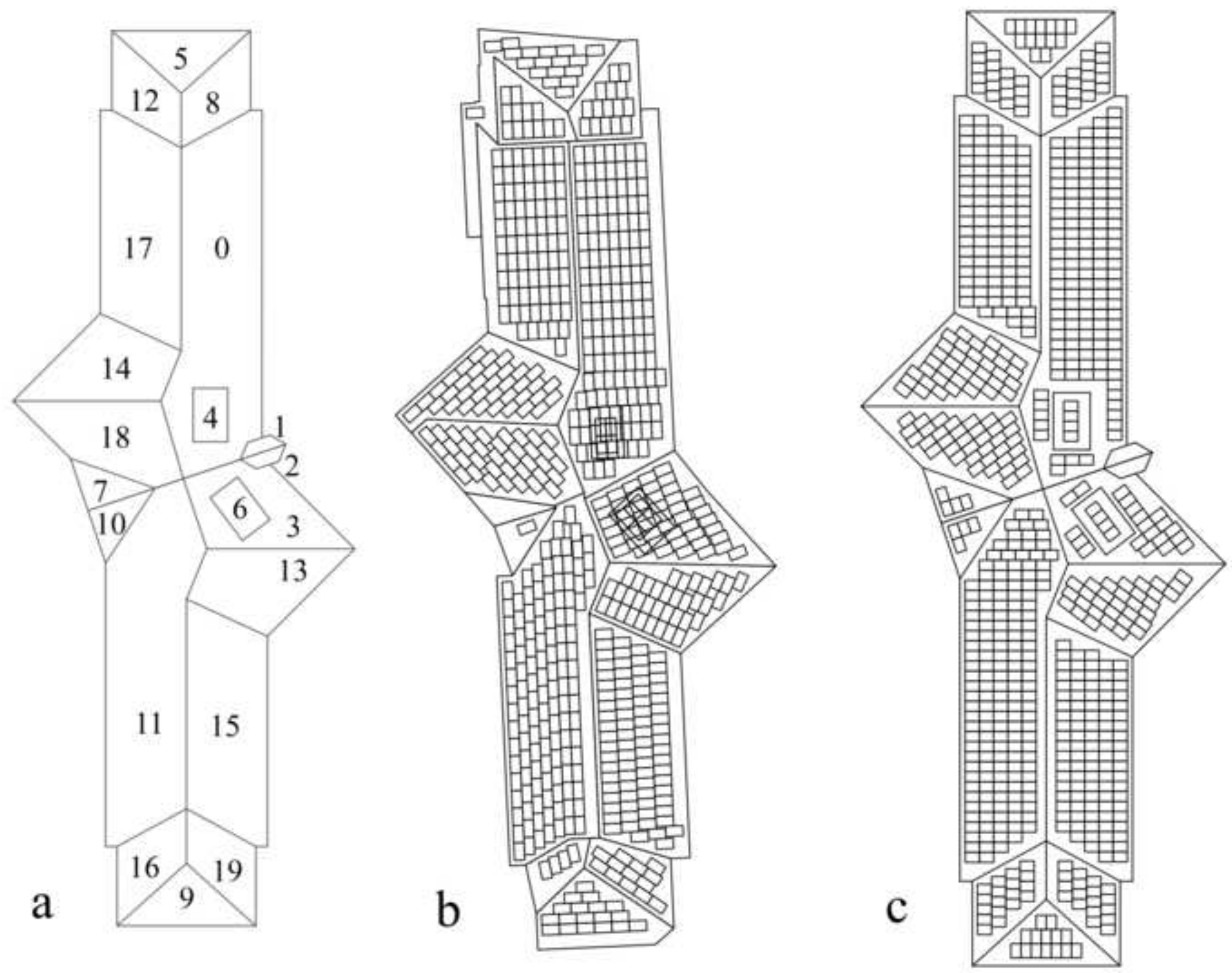

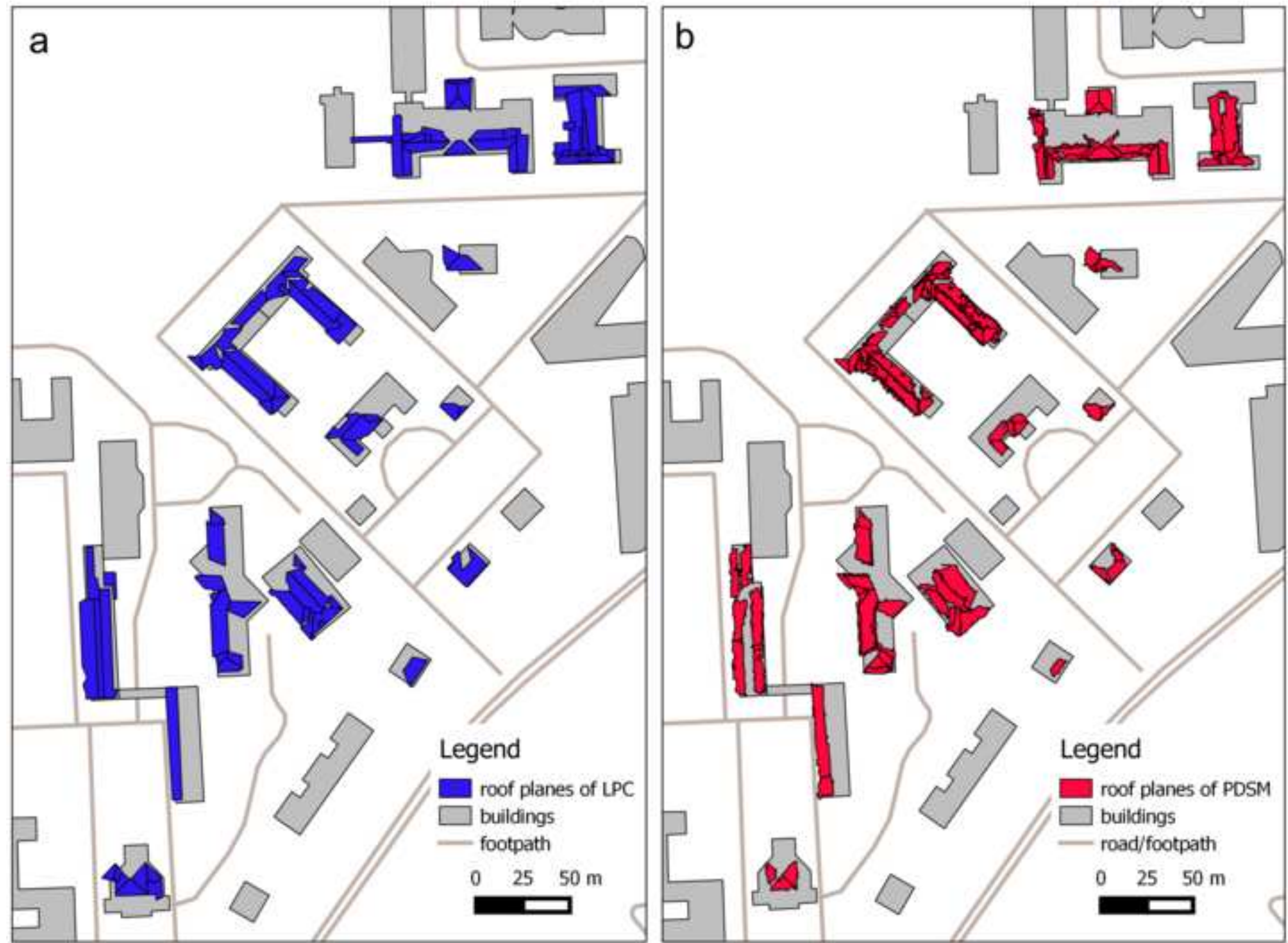

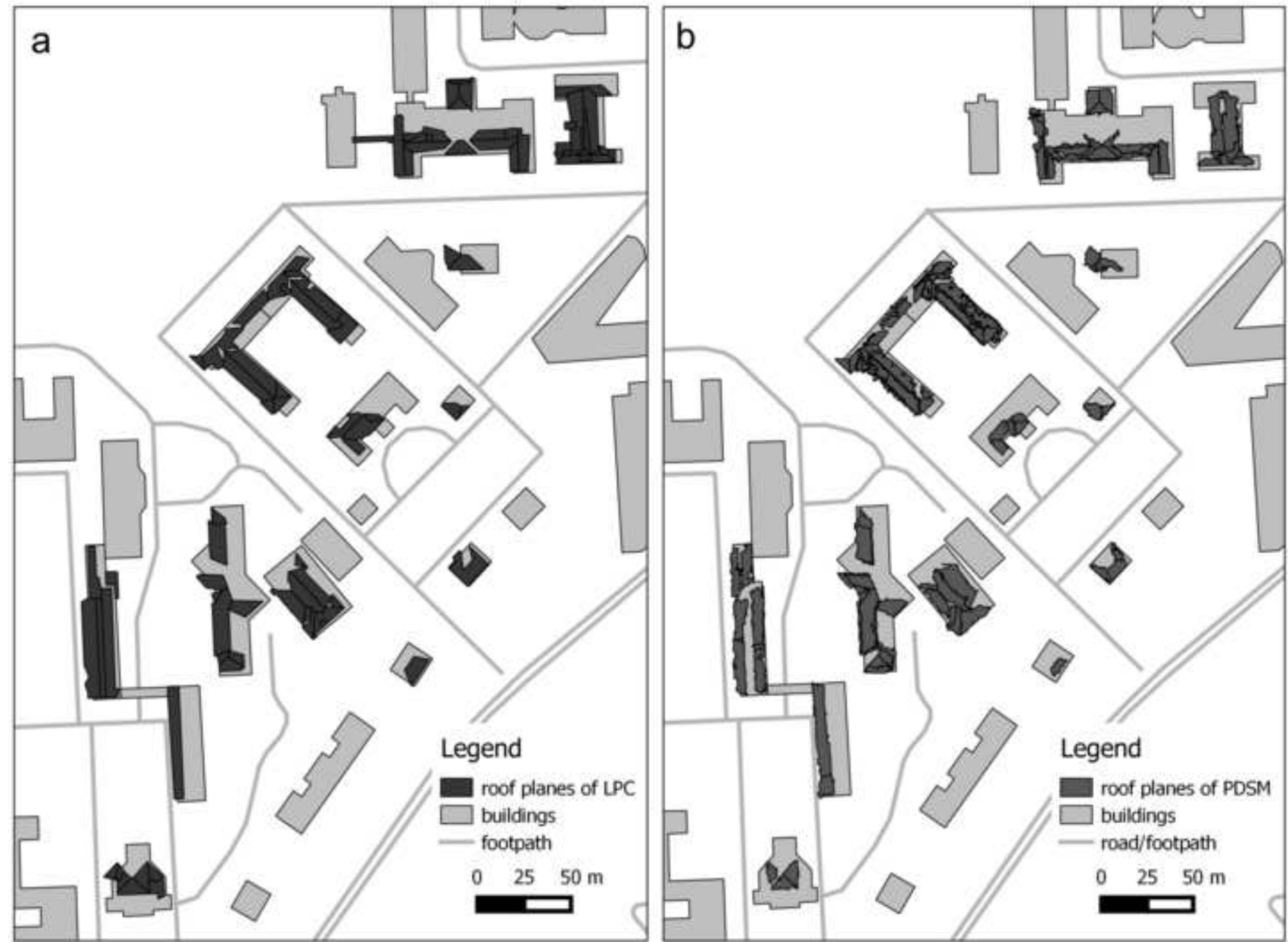